\title{
A CHEMICAL PRODUCT DESIGN COURSE WITH A QUALITY FOCUS
}

\author{
P. M. SARAIVA and R. COSTA* \\ GEPSI-PSE Group, Department of Chemical Engineering, University of Coimbra, Coimbra, Portugal
}

I $\mathrm{n}$ recent years the chemical processes industry has faced important social, technical and economical challenges. As a result, the nature of its products, business strategies and ultimately the needs associated with the skills and technical knowledge of chemical engineers suffered enormous evolutions. One of such main changes is related to the emergence of chemical product design (CPD) as a specific and critical new field within the scope of chemical engineering. The importance of CPD teaching in chemical engineering courses is becoming well recognized by a number of different and leading universities. This paper presents a CPD course conceived and taught at the University of Coimbra to final year students in a fiveyear chemical engineering degree. It was developed with a special focus on the connections between CPD and quality engineering tools. The course was considered as a product by itself and conceived as such, namely through a clear identification of its strategic scope (mission, vision and values), aims (skills to be developed and knowledge to be acquired) and structural features (functional organization, time allocation, learning practices, programmatic contents and performance appraisal). A sample of two specific chemical product design projects carried out by teams of students is also described. This teaching experience has been very rewarding and stimulating from the perspectives of both faculty and students. It shows that CPD is indeed a new discipline that can and should be offered to more and more chemical engineering students all over the world, and that it can gain a lot through the application of quality management principles and quality engineering tools.

Keywords: chemical product design; chemical engineering education; quality engineering; quality tools.

\section{INTRODUCTION}

The chemical processes industry has faced important social, technical and economical challenges all over the world, on a global and local scale. As a result, it has suffered deep and rapid changes in the nature of its products and in the strategies adopted to remain profitable and achieve sustainable growth (Figure 1). The plants of today and tomorrow do not have much in common with those of twenty years ago. Consequently, the portfolio of needs concerning skills and technical knowledge for chemical engineers and new generations of professionals in this field must correspond to these realities, placing new demands and challenges on the universities where they are trained.

Regarding social issues, there are stronger and stronger demands for environmental sustainability and protection. Moreover, the chemical industry has been regarded as an agent responsible for quality of life improvement, including

*Correspondence to: Eng. R. Costa, GEPSI-PSE Group, Department of Chemical Engineering, University of Coimbra, 3030-290, Coimbra, Portugal. E-mail: raquel@eq.uc.pt disease prevention and cure and poverty exclusion in the world. Such social concerns need to be reflected in the education, values and ethics of chemical engineers (Allen and Shonnard, 2002; Brennecke and Stadtherr, 2002; Holliday et al., 2002; Sikdar and El-Halwagi, 2001; Stroebe et al., 2001).

Technically, the chemical processes industry needs to address critical issues such as the continuous reduction in energy and materials consumption, process intensification and integration and the capability of dealing with a multiscale perspective, ranging all the way from the atomic or nanoscale to the macroscale of markets and supply chain management (e.g. Charpentier, 2002).

As far as economical issues are concerned, globalization has opened new markets, but at the same time it has resulted in a number of considerable threats. Additionally, the chemical industry has had to deal with increasingly dynamic markets and customers strongly aware and demanding as to quality and performance of the products that they buy.

As result of the challenges described above, the chemical processes industry has undergone great changes in the 


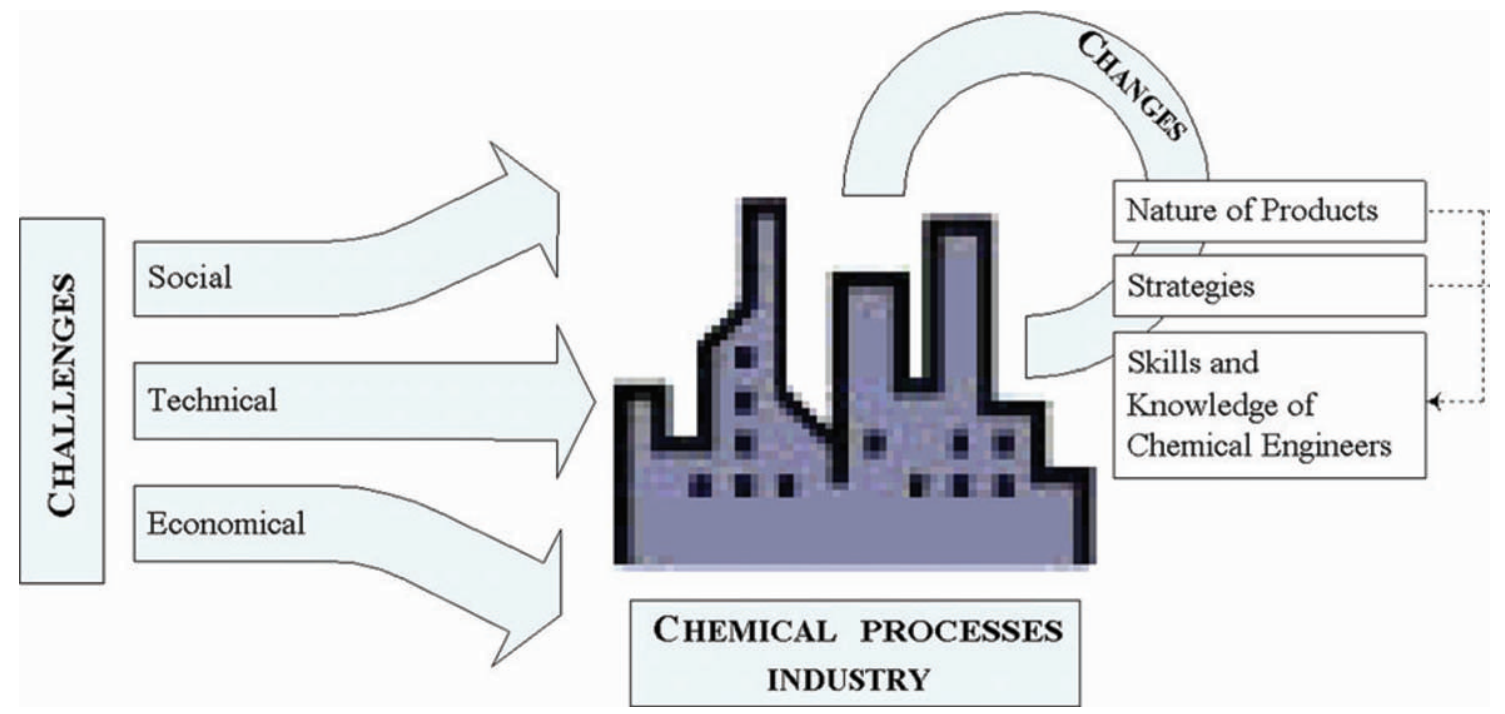

Figure 1. Challenges and changes in the chemical processes industry.

scope of its activity, management strategies adopted and ultimately in the needs associated with the new generation of chemical engineers that it is employing now and/or will employ in the future (quite different from the typical ones related to the petrochemical industry environment of twenty years ago).

One of the main changes observed in the chemical industry concerns its evolution from commodities (compounds produced at a large scale and for which price becomes the critical purchasing criterion) to more sophisticated products. Indeed, at present, more than $50 \%$ of the chemical industry market corresponds to specialities (Favre et al., 2002). As opposed to commodities, specialties are compounds produced in small quantities (typically less than 1000 ton/year), of high added value and differentiated in the marketplace by quality and performance rather than just price. Formulated products (such as paints, cosmetics, soaps, pharmaceutical preparations, beverages and foods) also now represent a large fraction of the chemical industries' business. They can be defined as combined systems (typically with four to 50 components) designed to meet end-use properties (Favre et al., 2002). These systems can be stated as being multifunctional (because they accomplish more than one function valued by the customer) and microstructured (since their value derives mostly from their microstructure) (Moggridge and Cussler, 2000). In addition, biobased concepts, genomic and postgenomic solutions, tissue and metabolic engineering technologies, as well as biomedical and body building challenges, are now part of the chemical engineering vocabulary.

As illustrated by Figure 2, based on the records of graduates from the Universities of Cambridge and Minnesota (Cussler and Moggridge, 2001), these shifts in the chemical processes industry have resulted in clear changes in the chemical engineering profession. The fraction of chemical engineers working in commodities decreased by more than a factor of three while the percentage of those focused on products (specialties and formulated products) increased from 15 to $50 \%$ in the past twenty-five years. Regarding sectors of activity, while twenty years ago petrochemical companies provided most of the available chemical engineering jobs, at present demand covers a wide spectrum, including sectors such as electronics, food/consumer products, biotechnology and engineering services (design, construction, research and testing) (Cussler and Wei, 2003; Grossmann, 2003).

Additionally to the changes already listed in the nature of their products, chemical process industries have also undergone major changes in the adopted strategies to remain profitable and survive. These changes include increasing attention devoted to opportunities and modifications in management. As a result, the average number of jobs that a chemical engineer is going to experience throughout his/her career has already increased from two to seven (Moggridge and Cussler, 2000) and probably it will grow even further in the future.

Given all of the above challenges and changes, the words of Danckwerts (1966) are now more applicable than ever before:

It would be a great mistake to think of the content of chemical engineering science as permanently fixed. It is likely to alter greatly over the years, in response to the changing requirements of industry and to new scientific discoveries and ideas for their application.

In such an environment, it is critical for Chemical Engineering Departments to question themselves about the way they are building the new generations of chemical engin-

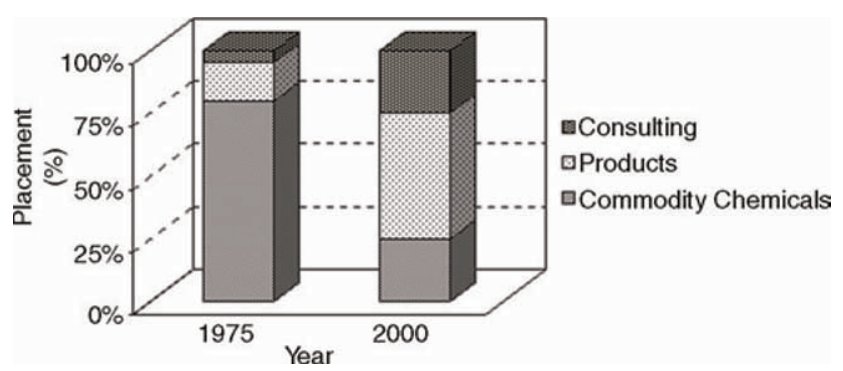

Figure 2. Changes in the jobs of chemical engineers. (Adapted from Cussler and Moggridge, 2001.) 
eers and, in particular, if their education is up to the present challenges, new realities and uncertainties about the evolution of markets, technologies and societies. In this context, the three major issues of concern briefly mentioned in the forthcoming paragraphs should be taken into account.

\section{New Problems Demand New Bodies of Knowledge}

Many of the current problems that the chemical industry is facing cannot be solved only through the classical body of knowledge connected with chemical engineering courses (a combination of balances, equilibrium and kinetics equations). Owing to the nature of the chemical products currently manufactured, new problems are emerging and demand other kinds of supplementary knowledge. In fact, to deal with these problems, chemical engineering must embody approaches and topics such as: rheology, transport across interfaces, transport phenomena in multicomponent systems (Favre et al., 2002), materials, powder technology, colloid chemistry and physics (Wesselingh, 2001). Chemical engineers must also be able to understand and apply methodologies that allow them to convert problem representation spaces all the way from customer needs to detailed technical specifications of the product-process binomial.

\section{Moving from Process Towards an Integrated Multifunctional Perspective}

Most of the relevant chemical engineering concerns of today are no longer exclusively placed at the level of process design and management, but rather demand an integrated, holistic and multiscale analysis in which products, processes, organizations, markets and competitors are viewed as a whole. This integrated view, ranging from nano- and microsystems to industrial-scale processes, has been conceived making use of the concepts of multiscale chemical engineering and chemical supply chain (Charpentier, 2002; Westerberg and Subrahmanian, 2000; Grossmann, 2003).

\section{Emergence of Chemical Product Design as a Branch of Chemical Engineering}

A logical consequence of the new environment that surrounds chemical companies and chemical engineers is the recognition and emergence of chemical product design (CPD) as a very important new field within the scope of chemical engineering, both from a research and a teaching perspective.

As a new field of chemical engineering, CPD intrinsically has a multiscale nature, ranging from the molecular scale to the macroscopic level. At the lowest scale, in the area of molecular product design, CAPD (computer-aided product design) is one of the most promising topics (e.g. Constantinou et al., 1996). On the other hand, at a macroscopic level, integrated approaches are being developed to provide a more efficient and faster design of chemical products able to answer market demands (Cussler and Moggridge, 2001; Westerberg and Subrahmanian, 2000; Wibowo and $\mathrm{Ng}, 2002)$. In general, these approaches are based on the idea that CPD is best achieved by making use of know-how not only from chemical engineering and related sciences but also from other areas of knowledge.
In fact, according to Westerberg and Subrahmanian (2000), CPD is a mixture of many talents (business, fine arts, social sciences and chemical and chemical engineering technology) to which quality management and quality engineering tools can be added.

The changes in the scope of chemical engineering described above must be followed by an evolution in research and education. In the words of Cussler and Wei (2003), chemical engineers have to re-invent themselves, and they need to look for a new paradigm so as to face up the challenges and changes observed in the chemical industry. As chemical engineering education is concerned, the importance of CPD teaching is becoming well accepted (e.g. Moggridge and Cussler, 2003). Cussler and Moggridge (2001) published the first textbook specifically addressing this field; some recent editions of process design books are devoting a chapter to this topic (e.g. Turton et al., 2003) and a number of different universities are beginning to offer CPD courses in their chemical engineering curricula. Without pretending to be exhaustive, a number of pioneering efforts in this context deserve notice here: Carnegie Mellon University has been offering for a number of years now a crossdisciplinary course on the design of engineered products with a strong focus on CPD (Westerberg and Subrahmanian, 2000); a CPD course is part of the required undergraduate curriculum at the University of Minnesota and at Cambridge University (Moggridge and Cussler, 2000); Wesselingh (2001) presents a CPD course provided as a joint effort between the Universities of Groningen and Oldenburg and the Deutsches Institut für Lebensmitteltechnik (DIL), a German food processing research centre; the Technical University of Denmark has also initiated teaching activities in CPD (Kontogeorgis et al., 2003); a product engineering course is offered by the University of Karlsruhe (Kind and Schuchmann, 2003); taking such efforts one step further, the Hong Kong University of Science and Technology provides a Chemical and Bioproduct Engineering graduation that emphasizes the application of engineering knowledge on the design of chemical and bioproducts, in what is believed to be the first undergraduate course dedicated mostly to this area.

At the Chemical Engineering Department of the University of Coimbra (one of the oldest universities in the world, founded in 1290), the first author of this article was asked to become responsible for the fifth year design course that the chemical engineering students need to take in their last year of studies. At that time, it was found to be appropriate to refresh the way this course was being offered in order to update its goals with the present and future needs of chemical engineers in the world as well as in Portugal. Therefore, the existing course was revamped, resulting in an annual design course where both Chemical Product and Chemical Process Design are covered in an integrated way, with the first semester centred around CPD and the second one devoted to Process Design (the only area covered before).

After a detailed design of the course (seen by itself as being a product that should be well designed), it was offered for the first time in academic year 2001/2002, in what is believed to be the first attempt to provide formal teaching of CPD in Portugal. 
During the conception of this course, the first author of this article was encouraged to do so and provided with materials developed by Professor Westerberg and his colleagues at Carnegie Mellon University, whom the authors would like to thank for their support.

Based on previous research, teaching and consulting experience in the field of quality, quality planning and engineering tools were judged as being able to provide a very important support to the teaching and practice of $\mathrm{CPD}$, namely regarding the use of methodologies such as Quality Function Deployment, FMEA, Design of Experiments, Robust Design, Design for Six Sigma or TRIZ (Altshuller, 1996; Burchill and Brodie, 1997; Lochner and Matar, 1990; Phadke, 1989; Pires, 1999; Plsek, 1997; Rantanen and Domb, 2002; Saraiva and Orey, 2000; Schmidt and Launsby, 1992; Stamatis, 1995). Therefore, the course was conceived from the beginning with a strong focus on the use of quality tools in the CPD process, a combination that was indeed found to be really powerful.

Just as it was very helpful for the authors being able to benchmark pre-existent CPD courses in other parts of the world, in the remaining parts of this article some of the experience acquired in conceiving and implementing such a course at the University of Coimbra is presented. Since CPD teaching evolved mostly already in the Internet era, one should be able to promote more and more exchanges of results, conclusions and materials in this new and fascinating field of Chemical Engineering.

For that purpose, the course strategic orientation and culture are first presented. Subsequently, the proper identification of its goals is considered. Then, the course concept, its underlying structure, technical characteristics and performance appraisal practices are described. This sequence illustrates the fact that the design of a CPD course can be seen as being by itself a CPD project, where the course stands as a very special case of a new product in its own right. Finally, some of the main course outputs are presented through a brief description of two different CPD projects car- ried out by teams of students during the semester. It is quite surprising to realize the variety and richness of chemical product design problems and solutions that the students were able to accomplish in such a short period of time (the course begins in September and ends by mid December). In the authors' view, such examples are the best way to provide evidence and enthusiasm for all of those involved in CPD teaching and to promote the diffusion of this area as one of the most promising in chemical engineering education and research.

\section{THE CPD COURSE AT THE UNIVERSITY OF COIMBRA}

The CPD course was included within the context of a traditional five-year chemical engineering graduation program (Figure 3), and offered for the first time in the academic year 2001/2002. It covered the fall semester (for a total of fifteen weeks, with six hours of classes plus six hours of additional work per week) as the first half of an integrated chemical product/process design annual course, with the second semester being devoted mostly to process design. However, it may also be offered as a standalone course with the same work load and a duration of one semester. After a renewal of the chemical engineering plan of studies at the University of Coimbra, which is now taking place, the course will become an elective fifth year course in such a context.

The conception and implementation of the CPD course followed the stages of a product design project by itself, resulting in a clear set of specifications, decisions and options (Figure 4). Right at the beginning, an effort was made to speak with five key people from industry, whose voices of the customer regarding the needs around Product and Process Design were collected and used as important inputs, together with the adoption of benchmarking through the collection of information about other CPD courses being offered in the world and exchange of experiences with their professors.

\begin{tabular}{|c|c|c|c|c|c|c|}
\hline \multirow[b]{2}{*}{$\begin{array}{c}\text { Academic Year } \\
2001 / 2002\end{array}$} & \multicolumn{2}{|l|}{ YEAR 1} & $>$ YEAR 3 & YEAR 4 & \multirow[b]{2}{*}{$\begin{array}{l}\text { - Management } \\
\text { - Powder technology } \\
\text { - Environment } \\
\text { - Design } \\
\text { - Research project }\end{array}$} & \multirow[b]{2}{*}{ CPD Course } \\
\hline & $\begin{array}{l}\text { - Mathematics } \\
\text { - Physics } \\
\text { - Chemistry } \\
\text { - Computers }\end{array}$ & $\begin{array}{l}\text { - Mathematics } \\
\text { - Physics } \\
\text { - Chemistry } \\
\text { - Computers } \\
\text { - Applied statistics }\end{array}$ & $\begin{array}{l}\text { - Transport } \\
\text { phenomena } \\
\text { - Thermodynamics } \\
\text { - Mass and energy } \\
\text { balances } \\
\text { - Instrumentation }\end{array}$ & $\begin{array}{l}\text { - Process modelling } \\
\text { and simulation } \\
\text { - Process control } \\
\text { - Unitary operations } \\
\text { - Chemical reactors } \\
\text { - Electricity and } \\
\text { electronics } \\
\text { - Options }\end{array}$ & & \\
\hline 自 & YEAR 1 & YEAR ? & YEAR 3 & & & \\
\hline $\begin{array}{c}\text { Academic Year } \\
\text { 2007/2008 }\end{array}$ & $\begin{array}{l}\text { - Mathematics } \\
\text { - Physics } \\
\text { - Chemistry } \\
\text { - Computers }\end{array}$ & $\begin{array}{l}\text { - Mathematics } \\
\text { - Chemistry } \\
\text { - Computers } \\
\text { - Applied statistics } \\
\text { - Transport } \\
\text { phenomena } \\
\text { - Thermodynamics }\end{array}$ & $\begin{array}{l}\text { - Transport } \\
\text { phenomena } \\
\text { - Mass and energy } \\
\text { balances } \\
\text { - Chemical reactors } \\
\text { - Powder technology } \\
\text { - Biological } \\
\text { processes }\end{array}$ & $\begin{array}{l}\text { - Instrumentation } \\
\text { - Process modelling } \\
\text { and simulation } \\
\text { - Process control } \\
\text { - Unitary operations } \\
\text { - Management } \\
\text { - Environment } \\
\text { - Options }\end{array}$ & $\begin{array}{l}\text { - Process design } \\
\text { - Research project } \\
\text { - Options }\end{array}$ & CPD Course \\
\hline
\end{tabular}

Figure 3. Position of the CPD course in the chemical engineering undergraduate course at the University of Coimbra. 


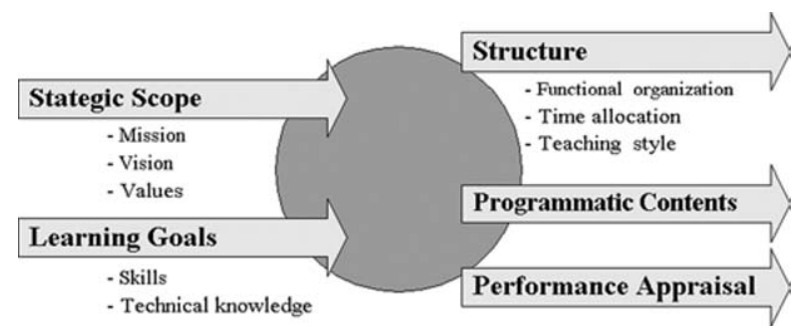

Figure 4. Design of our CPD course.

Finally, mechanisms of communication with students were put into place, in order for their feedback and suggestions to be also duly taken into account. As in the case of a truly industrial CPD project, a step-by-step approach was followed leading to the definition of the course. In the forthcoming paragraphs the main inputs and outputs for each of these steps are illustrated.

\section{Strategy, Culture and Concept}

The CPD course exists within the scope of an organizational context which basically consists of a community that comprises faculty members, guest speakers and students. Therefore, it was decided that before jumping directly into the detailed product definition it was important to clarify and make explicit what the strategy, culture and course concept should be made from, so that any options made later on could be made consistent with such choices.

The following description was thus adopted for the CPD course mission:

To contribute, through a participative learning process, to the training of chemical engineers that are able to be successfully integrated within product development teams, to play an active role in the design of chemical products (including specialty chemicals and formulated products) and to use properly available quality tools.

Such a mission is complemented through the consideration of the course vision as stated below:

To be an increasingly better reference course in the teaching of CPD to undergraduate chemical engineering students with a quality focus.

Additionally, a number of values that the CPD course should promote and according to which its community (teachers and students) should behave was set (Table 1).

In order to align behaviour with the course strategy and culture, these were discussed right at the beginning. At that time both teacher and students were asked to sign a written document through which they commit mutually to acknowledge and agree with the options made and behave according to the values and rules agreed upon and established in the

\begin{tabular}{l} 
Table 1. Course main values. \\
\hline Active participation \\
Assiduity \\
Continuous learning \\
Dedication \\
Honesty \\
Mutual respect \\
Open mindedness \\
Professionalism \\
Fulfilment of rules and timings
\end{tabular}

very first class of the semester (regarding individual and collective behaviour). This written learning commitment was found to be a quite effective way of establishing mutual respect and promoting alignment of attitudes towards the assumed CPD course strategy and culture.

Also at this stage the product concept was established taking into account many of the customer voices, information collected and experience obtained so far. The purpose was to build a CPD course with the following main features (summarized under the heading of A Chemical Product Design Course with a Quality Focus, which also stands as the title for the present article):

- a strong focus around the use of quality management principles and tools;

- close links with industrial practice;

- combination of 'soft' and 'hard' components in a balanced way;

- practical open problem, project and team oriented.

As in any real industrial CPD project, the above options did set up inspiring guidelines for all the forthcoming decisions made at a more operational level under the leadership of a product champion (in this case, the course professor).

\section{Aims}

With the strategic choices already made, as illustrated above, and a definition of the general product design orientations associated with the product concept, it was now time to move into the definition of a set of learning goals to be accomplished regarding the development of skills as well as the acquisition of technical knowledge by the students.

In spite of the fact that employers tend to value more and more skills, rather than just technical knowledge, higher education tends to neglect such concerns and concentrate mostly around the transfer of technical knowledge from professors to students. With the intention of avoiding this limitation, some of the key competencies that the CPD course should stimulate and develop were enumerated (Table 2). The pedagogical style adopted, types of classes considered, performance appraisal criteria used and other related issues were then designed in order to accomplish such goals of skills development.

Looking now more strictly into technical knowledge acquisition, the course is basically aimed at having the students learning about and practicing the several steps

Table 2. Skills developed by the course.

\begin{tabular}{l}
\hline Addressing uncertainties \\
Communication \\
Control \\
Customer-driven attitude \\
Creativity \\
Evaluation \\
Initiative \\
Innovation \\
Leadership \\
Open problem formulation and solution \\
Organization \\
Overcoming difficulties \\
Planning \\
Team work
\end{tabular}


involved in the efficient creation, development and launching of a chemical product able to meet customer needs. Furthermore, it is also intended to make students aware of which tools are available to cope with each of the steps of the chemical product development process briefly illustrated in Figure 5. As it will be seen later on, the programmatic contents do correspond to such goals, providing a general coverage of the process steps, their associated tasks and techniques used to address them.

With the course goals and customer needs properly identified and its concept chosen, it was then the time to move into the space of solutions, in order to come up with a set of features for the CPD course that would make it correspond to and meet the desired goals. For the sake of clarity, such features are next presented separately as (i) course structure characteristics, (ii) detailed technical contents and (iii) performance appraisal procedure.

\section{Course Structure}

As stated before, the structural choices are essential in order for the CPD course to be able to accomplish its goals related with skills development.

The basic building block for learning activities is not the individual student, but rather teams comprising five to seven students (below this size no real group dynamics are going to occur and in real CPD industrial practice much larger team sizes are in place). Each year about ten such teams exist and attend the course. These teams are formed in the first class, and obliged to choose a nickname and a logo for themselves. They are then kept with the same composition for the complete semester, during which time they are asked to solve a number of increasingly more complex open-ended CPD-related problems and challenges.

Roughly a quarter of the lecture time corresponds to presentations made by special guests from industry with practical design experience, mostly from the chemical industry but also from other sectors (in authors view, it is important to have always someone from the automotive sector, given its quite advanced practices of product design and development, as well as guests from robotics and pharmaceutical industries). As for the remaining classes, an interactive style is adopted, so that the different concepts and techniques are presented and discussed with students. This is followed step by step with practical open-ended exercises that the students address during the class through extensive teamwork. Furthermore, time is also allocated for teams to present their planning of tasks, progress and final reports about the problems that they are trying to address.

\section{Programmatic Contents}

The CPD course touches many of the aspects involved in new product development (from strategic fitting, planning and management of projects to economic profitability

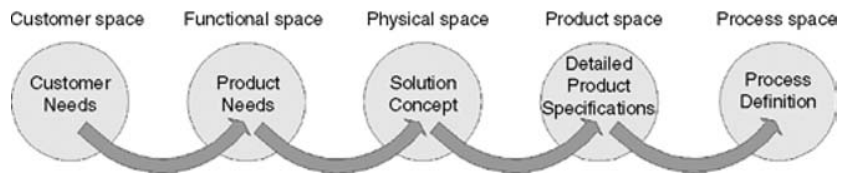

Figure 5. Major steps involved in the chemical product design process. analysis), but it clearly emphasizes the development and design of chemical product concepts and specifications with a quality focus around some of the proposed techniques for doing so. The final goal is to build a sequence of translations that transform customer needs into a completely specified product (Figure 5).

In general, the course contents do follow the CPD approaches proposed by Cussler and Moggridge (2001) and by Wibowo and $\mathrm{Ng}$ (2002) as well as the Product Development steps mentioned namely by Anderson (2000), Dimancescu and Dwenger (1996), Dym and Little (2000), Rosenau et al. (1996), Saraiva and Orey (2000) and Ulrich and Eppinger (2003), according to the following seven major sequential areas: (1) introduction and overview of CPD; (2) identification of customer needs and translation of needs into product functional requirements; (3) generation of product concepts; (4) selection of a final product concept to be developed; (5) definition of detailed specifications for the product concept chosen; (6) moving from product to scaling-up and process design; and (7) design under uncertainty, conclusions and lessons to learn from the course.

During several weeks, many methodologies and tools are presented, originating from fields such as marketing, quality and creativity. As far as possible they are seen from a technical point of view, integrated with chemical engineering background and applied to CPD problems.

Table 3. Course typical syllabus: introduction area.

\begin{tabular}{|c|c|c|}
\hline CPD step & Contents and tools covered & $\begin{array}{l}\text { Course } \\
\text { weeks }\end{array}$ \\
\hline Introduction & $\begin{array}{l}\text { Course strategy, culture, rules, ethics and } \\
\text { goals } \\
\text { Team formation } \\
\text { Mutual commitment to the course } \\
\text { Chemical product design vs process design } \\
\text { Synthesis and analysis components of design } \\
\text { Project planning and management } \\
\text { Reverse chemical engineering } \\
\text { Commodities vs specialties } \\
\text { Mixtures and formulated products } \\
\text { Some good and bad examples of product } \\
\text { design } \\
\text { Robust product design } \\
\text { Chemical product design and life cycle } \\
\text { analysis } \\
\text { Time to market } \\
\text { Trends in new product development } \\
\text { Problem representations and testing of } \\
\text { solutions } \\
\text { The sequential paradigm of product } \\
\text { development } \\
\text { Concurrent engineering } \\
\text { Quality function deployment } \\
\text { Multidisciplinary product design teams } \\
\text { Innovation sources } \\
\text { Customer orientation in new product design } \\
\text { Chemical product design as a sequence } \\
\text { of translations } \\
\text { Speed, cost and quality in CPD } \\
\text { Relevance of concept engineering } \\
\text { Specific case studies } \\
\text { Combinatorial chemistry and rapid testing } \\
\text { Rate of creation of new chemical compounds } \\
\text { The relevance of CPD in chemical } \\
\text { engineering } \\
\text { Goals of CPD } \\
\text { Major CPD steps }\end{array}$ & $1-2$ \\
\hline
\end{tabular}


Table 4. Course typical syllabus: needs area.

\begin{tabular}{|c|c|c|}
\hline CPD step & Contents and tools covered & $\begin{array}{l}\text { Course } \\
\text { weeks }\end{array}$ \\
\hline Needs & $\begin{array}{l}\text { Collection of customer voices } \\
\text { Selection of lead users } \\
\text { Exploratory interviewing techniques } \\
\text { Applications } \\
\text { Conversion of customer voices } \\
\text { into needs } \\
\text { Treatment of customer needs } \\
\text { Affinity diagrams } \\
\text { Iterative selection method } \\
\text { Kano analysis } \\
\text { Importance and types of customer } \\
\quad \text { needs } \\
\text { Profile of customer needs for winning } \\
\text { products } \\
\text { Benchmarking } \\
\text { Illustrative examples } \\
\text { Structured trees of customer needs } \\
\text { Definition of product performance functional } \\
\text { metrics and goals } \\
\text { Case studies } \\
\text { Final validation, verification and preliminary } \\
\text { evaluation of product functional goals } \\
\text { Application }\end{array}$ & $3-6$ \\
\hline
\end{tabular}

Tables 3-9 show the typical syllabus associated with the CPD course, which covers a broad spectrum of topics, ranging from customer voice identification to scaling up and interfacing between product and process design. The particular focus around quality management principles and quality engineering tools was found to be fruitful, since they tie in perfectly with the kind of practical needs associated with the several CPD tasks that the teams of students are asked to accomplish.

In the last week of classes, some of the research work done in the GEPSI-PSE Group in the area of chemical product/process design under uncertainty (Bernardo et al., 2001; Bernardo and Saraiva, 2003, 2004) is shared with the students, since this topic crosses all CPD steps and is critical for understanding why design is, above all, a constant fight against uncertainties that one has to cope with and try to reduce as much as is economically justifiable.

The course closes with presentations of the final CPD projects carried out during the semester by the several teams of students.

\section{Performance Appraisal}

All people in general, but students in particular, behave to a large extent depending upon the recognition and

Table 5. Course typical syllabus: ideas area.

\begin{tabular}{llc}
\hline CPD step & \multicolumn{1}{c}{ Contents and tools covered } & $\begin{array}{c}\text { Course } \\
\text { weeks }\end{array}$ \\
\hline & $\begin{array}{l}\text { Creativity principles and tools } \\
\text { Brainstorming }\end{array}$ & $7-9$ \\
& Sources of creativity for CPD & \\
Ideas & TRIZ & \\
& Computational chemistry and genetic algorithms \\
& Case studies \\
& Morphological charts & \\
\hline
\end{tabular}

Table 6. Course typical syllabus: selection area.

\begin{tabular}{llc}
\hline CPD step & Contents and tools covered & Course weeks \\
\hline & Multicriteria optimization & \\
& Pareto optimal concepts & \\
& Moving from 100 to 20 ideas & \\
& Moving from 20 to five ideas & \\
Selection criteria and matrixes & \\
Selection & Benchmarking \\
& Case studies \\
& Selection of a winning concept \\
& Pugh methodology and matrix \\
& Risk analysis \\
& FMEA \\
& Application \\
\hline
\end{tabular}

reward systems used and applied to them. Therefore, one has to be quite careful in addressing this issue.

Rather than speaking about student evaluation, in the CPD course performance appraisal is referenced to the course assumed strategy, culture and goals. Such a performance appraisal system is also discussed with students before it becomes totally defined. It is inspired by a number of guiding principles:

- consistency with the course strategy, culture and goals;

- continuous and integrated performance evaluation;

- team-based;

- combination of self-assessment together with peer and external components;

- coverage of both skill development and technical knowledge acquisition.

Self-assessment is first conducted by the individual students, who fill out a form where they evaluate their evolution in terms of skills and technical knowledge acquired across the semester. This information is then discussed together with the other team members, who provide their own opinions and evaluations as well. Furthermore, at each presentation made in the classes, each group assesses its own performance as well as that it believes other groups have achieved through the use of a common grid of evaluation. All the problems that the teams have to solve in the classroom, as well as outside it, are also taken into account for grading purposes. Teams are also allowed to suggest that different grades should be assigned to some of its

Table 7. Course typical syllabus: specifications area.

\begin{tabular}{llr}
\hline CPD step & \multicolumn{1}{c}{ Contents and tools covered } & $\begin{array}{c}\text { Course } \\
\text { weeks }\end{array}$ \\
\hline & Definition of product technical specifications & $12-13$ \\
& Value analysis & \\
& House quality & \\
& Validation and optimization & \\
& Prototypes & \\
& Sources of commercial information & \\
Specifications & Economic evaluation & \\
& Design of experiments & \\
& Taguchi methods & \\
& Product robustness & \\
& Design for six sigma & \\
& Design for life cycle & Design for environment \\
& Design for process &
\end{tabular}


Table 8. Course typical syllabus: from product to process area.

\begin{tabular}{clc}
\hline CPD step & \multicolumn{1}{c}{ Contents and tools covered } & $\begin{array}{c}\text { Course } \\
\text { weeks }\end{array}$ \\
\hline & $\begin{array}{l}\text { Pilot plants } \\
\text { Scaling up and scaling down }\end{array}$ & 14 \\
From product & $\begin{array}{l}\text { Interactions among product and process } \\
\text { design }\end{array}$ & \\
& $\begin{array}{l}\text { Quality function deployment } \\
\text { Feasibility studies and product launching } \\
\text { Moving from product to product/process }\end{array}$ \\
\hline
\end{tabular}

Table 9. Course typical syllabus: conclusion area.

\begin{tabular}{llc}
\hline CPD step & Contents and tools covered & $\begin{array}{c}\text { Course } \\
\text { weeks }\end{array}$ \\
\hline Conclusion & $\begin{array}{l}\text { Uncertainty handling in product/process } \\
\text { design } \\
\text { Presentations of final CPD projects by } \\
\text { student teams } \\
\text { Discussion about the course and further } \\
\text { improvements }\end{array}$ & \\
\hline
\end{tabular}

members, under certain constraints. Moreover, evaluation bonus can be given to ideas conveyed by students regarding ways of further improving this CPD course.

Finally, a course Management Board (comprising the professor and one representative from each of the teams) is designated and meets weekly in order to evaluate how the course is proceeding and take improvement actions accordingly.

A large fraction of the final marks given to each student by the end of the semester has to do with the evaluation of an almost complete CPD project. In the next section two such projects, carried out by teams of students who attended the course in academic years of 2001/2002 and 2002/2003, are illustrated.

\section{A SAMPLE OF CPD PROJECTS CARRIED OUT BY TEAMS OF STUDENTS}

Besides a number of other smaller and partial exercises, teams of students are asked to develop a CPD project as completely as possible, with both written and oral presentations of progress and final results being made during the semester.

In these projects students must identify a new product opportunity and design it, applying the concepts and tools learnt across the semester. In the forthcoming paragraphs a brief description for a sample of two of such CPD projects is provided:

- 'Comfort in food and beverages' addresses the design of a portable system for cooling drinks on hot summer days;

- 'Informatics at home' deals with the conception of a new solid-based device as an alternative solution to the common ink cartridges currently employed by domestic printers.

It is believed that the illustration of these deliverables provides one of the best ways to convey the spirit, attitude,
Table 10. Needs that a portable drink cooling system should meet.

\begin{tabular}{llc}
\hline Obligatory needs & Unidimensional needs & Appealing needs \\
\hline Cool dinks & Have a realistic price & $\begin{array}{c}\text { Do not produce } \\
\text { unpleasant noise }\end{array}$ \\
$\begin{array}{l}\text { Be environmental } \\
\text { friendly }\end{array}$ & Be robust & \\
$\begin{array}{l}\text { Be safe } \\
\text { Operate quickly }\end{array}$ & & \\
\hline
\end{tabular}

culture, goals, skills and technical knowledge that the CPD course tries to develop.

\section{Comfort in Food and Beverages}

Opportunity identification

Many of the common daily problems are not yet solved, and some issues related to 'Comfort in food and beverages' are insufficiently developed, although they affect the quality of life of a large number of people with a reasonable purchasing power. Cooling of drinks is one of such issues. Many drinks, such as water, juice and beer, are commonly drunk as cool drinks, especially on hot summer days. It also happens to be the case that in some particular situations (e.g. on the beach, when travelling or hiking) current cooling systems (refrigerator, ice, thermic bottles and bags) cannot be used or do not perform efficiently. Thus, the field of portable drink cooling was seen as one where a new product could be successfully launched.

Needs

Needs were identified by interviewing potential customers (from various ages, jobs and social classes), café, restaurant and supermarket employees and drink manufacturers, distributors and wholesalers. Raw data gathered through the interviews led to a set of needs that a product in this area should be able to meet (Table 10), as well as to a number of performance metrics and targets to be achieved by a good solution (Table 11).

\section{Ideas creation and selection}

Ideas generation involved literature search and most importantly brainstorming within the team of students, resulting in a total of about sixty ideas. Then, redundancies and ideas that seemed unfeasible or unable to meet con-

Table 11. Translation of portable drink cooling system needs into product performance metrics.

\begin{tabular}{|c|c|c|}
\hline Needs & Metrics & Target \\
\hline Cool dinks & Temperature drop & $20^{\circ} \mathrm{C}$ \\
\hline Be environmental friendly & Panel of users assessment ${ }^{\mathrm{a}}$ & $\geq 8$ \\
\hline Be safe & Panel of users assessment ${ }^{\mathrm{a}}$ & $\geq 9$ \\
\hline Operate quickly & $\begin{array}{l}\text { Time to achieve drink } \\
\text { temperature drop }\end{array}$ & $1-\overline{5} \mathrm{~min}$ \\
\hline Have a realistic price & $\begin{array}{l}\text { Percentage of the price of } \\
\text { the drink to be cooled }\end{array}$ & $\leq 10 \%$ \\
\hline Be robust & Panel of users assessment ${ }^{\mathrm{a}}$ & $\geq 7$ \\
\hline $\begin{array}{l}\text { Do not produce } \\
\text { unpleasant noise }\end{array}$ & Panel of users assessment ${ }^{\mathrm{a}}$ & $\geq 7$ \\
\hline
\end{tabular}

${ }^{\text {a }}$ Range of assessment: $1-10$. 
Table 12. Five top ideas for a portable drink cooling system.

Device that performs drink cooling through an endothermic chemical reaction

Drink package with a system where an endothermic chemical reaction cools the contents

Capsule made by a polymer that allows for a one-way water flux; when water enters into the capsule an endothermic chemical reaction occurs and the drink gets cooled

Spray that cools the drink

Dry ice

Table 13. Possible salts to be used.

\begin{tabular}{|c|c|c|c|}
\hline & \multicolumn{3}{|c|}{ Salts } \\
\hline & $\mathrm{NH}_{4} \mathrm{NO}_{3}$ & $\mathrm{Na}_{2} \mathrm{~S}_{2} \mathrm{O}_{3} \cdot 5 \mathrm{H}_{2} \mathrm{O}$ & $\mathrm{Na}_{2} \mathrm{~S} \cdot 9 \mathrm{H}_{2} \mathrm{O}$ \\
\hline Mass needed (g) & 4.95 & 8.78 & 5.77 \\
\hline $\begin{array}{l}\text { Price of the quantity } \\
\text { needed }(€)\end{array}$ & 0.15 & 0.05 & 0.12 \\
\hline \multirow[t]{2}{*}{ Hazards } & Explosive & $\begin{array}{l}\text { Does not } \\
\text { present } \\
\text { hazards }\end{array}$ & $\begin{array}{l}\text { Provokes } \\
\text { burning }\end{array}$ \\
\hline & $\begin{array}{c}\text { Releases toxic } \\
\text { vapours }\end{array}$ & & $\begin{array}{l}\text { Releases } \\
\text { toxic } \\
\text { vapours } \\
\text { Irritating }\end{array}$ \\
\hline
\end{tabular}

straints such as obligatory needs or legal requirements were removed, resulting in twenty surviving concepts. The use of a concept-screening matrix lowered this number to a set of five winning ideas (Table 12). After applying the Pugh methodology, a final product concept emerged, which consisted of mixing a certain salt, whose dissolution was endothermic, with water. The particular salt to be used was chosen according to criteria such as (Table 13): (1) mass of salt needed to reduce by $20^{\circ} \mathrm{C}$ the temperature of $20 \mathrm{cl}$ of water (depending on the dissolution enthalpy); (2) price of the quantity of salt needed to carry out the cooling; and (3) hazards involved. As a result, $\mathrm{Na}_{2} \mathrm{~S}_{2} \mathrm{O}_{3} \cdot 5 \mathrm{H}_{2} \mathrm{O}$ was selected because, although a larger mass of this salt is needed, it is cheaper and does not involve any significant hazards, as opposed to other alternatives that were also evaluated.

\section{Product specifications}

As for the final product specifications, a detailed complete device was conceived (Figure 6). Two independent parts compose this device: a staff containing water $\left(15 \mathrm{~cm}^{3}\right)$ and a recipient where the salt is placed $(8.78 \mathrm{~g})$ and where dissolution occurs. The staff is made from a biopolymer with a reasonable percentage of starch and the recipient is made from a steel alloy with a large heat transfer coefficient. When the staff is coupled to the salt recipient, water flows into it and the dissolution occurs. Then the full device is placed in the glass containing the drink to be cooled. A prototype of this complete device, designated Chemicool, was actually built and tested with quite positive results.

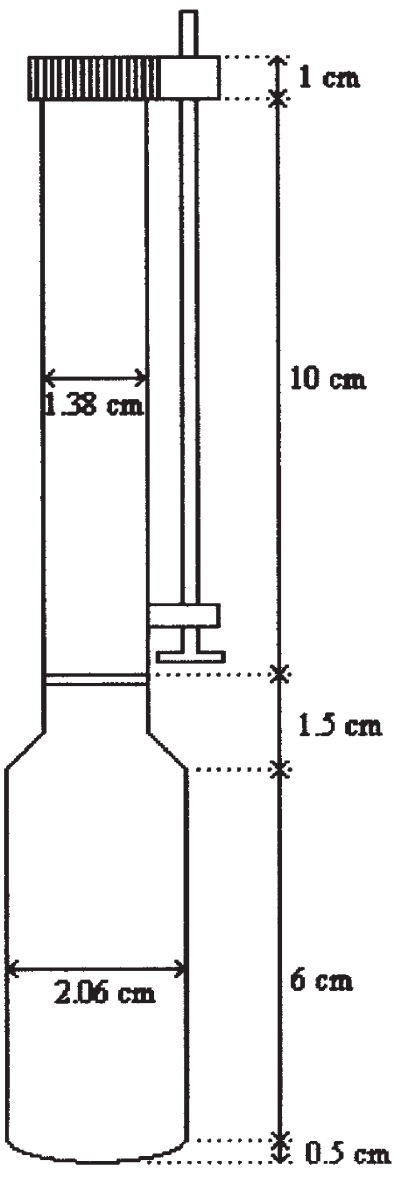

Figure 6. Schematic diagram of the portable drink cooling system.

\section{Informatics at Home}

Opportunity identification

In the last decade an informatics evolution has taken place not only at an industrial scale but also at home. Nowadays, computers and printers are present in most houses, and, as a result, informatics consumer goods are responsible for an increasingly larger portion of urban waste. Thus the field of environmental friendly informatics consumer goods (particularly with regard to ink cartridges) was perceived as one where a new product could be successfully launched.

Table 14. Needs for an environmentally friendly ink cartridge.

\begin{tabular}{|c|c|c|}
\hline Obligatory needs & Unidimensional needs & Appealing needs \\
\hline Print & Have high durability & $\begin{array}{l}\text { Does not produce } \\
\text { unpleasant smell }\end{array}$ \\
\hline Be tight & Ink is not toxic & Be easily recharged \\
\hline Have a low price & $\begin{array}{l}\text { Ink does not dry in the } \\
\text { cartridge }\end{array}$ & $\begin{array}{l}\text { Allows one to assess } \\
\text { ink level }\end{array}$ \\
\hline $\begin{array}{l}\text { Printed ink resists } \\
\text { to solar radiation }\end{array}$ & & $\begin{array}{l}\text { Be environmental } \\
\text { friendly }\end{array}$ \\
\hline \multirow{2}{*}{$\begin{array}{l}\text { Ink dries quickly on } \\
\text { the paper }\end{array}$} & & Print special colours \\
\hline & & $\begin{array}{l}\text { Ink has good adherence } \\
\text { to any support }\end{array}$ \\
\hline
\end{tabular}


Table 15. Performance goals for an environmental friendly ink cartridge.

\begin{tabular}{|c|c|c|}
\hline Needs & Metrics & $\begin{array}{c}\text { Product } \\
\text { specifications }\end{array}$ \\
\hline Be tight & $\begin{array}{l}\text { Panel of users } \\
\text { assessment }^{\mathrm{a}}\end{array}$ & $\geq 9$ \\
\hline Have a low price & $\begin{array}{l}\text { Price (including all } \\
\text { colours available) }\end{array}$ & $\leq 50 €$ \\
\hline $\begin{array}{l}\text { Printed ink resists to } \\
\text { solar radiation }\end{array}$ & $\begin{array}{l}\text { Percentage of ink } \\
20 \text { years after printing }\end{array}$ & $\geq 80 \%$ \\
\hline $\begin{array}{l}\text { Ink dries quickly on the } \\
\text { paper }\end{array}$ & Drying time & $\begin{array}{l}\leq \text { Printing } \\
\text { time }\end{array}$ \\
\hline Have high durability & $\begin{array}{l}\text { Minimum number of } \\
\text { printed pages }\end{array}$ & 2000 to 3000 \\
\hline Ink is not toxic & Panel of biological tests & $\geq \operatorname{good}$ \\
\hline $\begin{array}{l}\text { Ink does not dry in the } \\
\text { cartridge }\end{array}$ & $\begin{array}{l}\text { Time period without } \\
\text { losing features }\end{array}$ & 1 year \\
\hline $\begin{array}{l}\text { Does not produce } \\
\text { unpleasant smell }\end{array}$ & $\begin{array}{l}\text { Panel of users } \\
\text { assessment }{ }^{\text {a }}\end{array}$ & $\geq 4$ \\
\hline Be easily recharged & $\begin{array}{l}\text { Panel of users } \\
\text { assessment }^{\text {a }}\end{array}$ & $\geq 8$ \\
\hline $\begin{array}{l}\text { Allows one to assess } \\
\text { ink level }\end{array}$ & $\begin{array}{l}\text { Error in ink level } \\
\text { detection }\end{array}$ & $\leq 20 \%$ \\
\hline $\begin{array}{l}\text { Be environmental } \\
\text { friendly }\end{array}$ & $\begin{array}{l}\text { Panel of users } \\
\text { assessment }{ }^{\mathrm{a}}\end{array}$ & $\geq 8$ \\
\hline
\end{tabular}

${ }^{\mathrm{a}}$ Range of assessment: $1-10$.

\section{Needs}

Needs were identified by interviewing potential customers (of various ages and jobs), informatics experts and sellers (Table 14), leading to a final set of product performance metrics and goals (Table 15).

\section{Ideas creation and selection}

Literature search and brainstorming within the team led in this case to a total of thirty-six different product ideas, whose number was then reduced to nine by eliminating repetitions and unfeasible alternatives. Then, a concept-screening matrix further reduced this number down to four (Table 16). From these and the application of the Pugh methodology a final winning concept was obtained.

\section{Product specifications}

The product was specified as a domestic ink cartridge composed of six independent transparent ink containers where ink solid sticks are put in (Figure 7). Stick containers are made from transparent polycarbonate, allowing one to assess the ink level. As for the solid ink sticks, they are composed of a wax to which pigments are added. Their formulation includes paraffin, an ethylene and vinyl acetate copolymer, amylamine fatty acids and pigments. Sticks of different colours are sold individually, with the following set of possibilities: magenta, blue, yellow, black, gold, silver and white. Heating systems associated with each wax container are needed, being made from aluminium

Table 16. Alternatives for an environmental friendly ink cartridge.

Ink vessel with biodegradable charges

Transparent ink vessel attached to the printer, able to be recharged, separated from printing heads

Low toxicity ink sold separately from cartridge

Transparent ink cartridge where ink is put in as wax sticks of different colours and sold individually
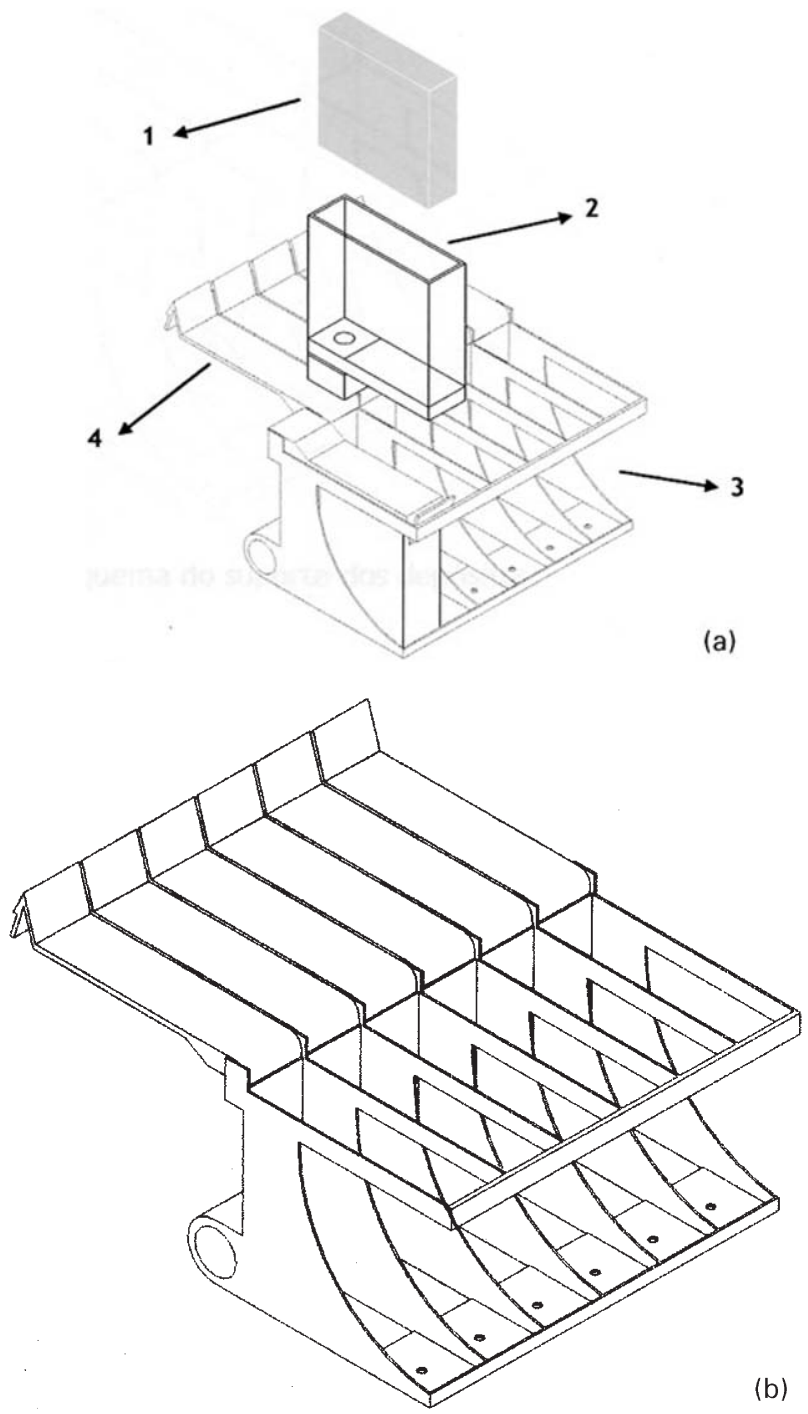

Figure 7. Schematic diagrams of the environmental friendly ink cartridge: (a) general view (1, wax stick; 2, stick container; 3, container support; 4, container lid); (b) ink cartridge container details (1, wall; 2, heating system; 3, draining zone; 4, printing head; 5, discharge hole).

sheets and electric resistances. Through heating, an ink liquid film is formed in the base and flows to the inkjet printing head.

\section{CONCLUSIONS}

The teaching of CPD to chemical engineering undergraduate and graduate students has been recognized as an important answer to current and future needs associated with the profession and employment of chemical engineers.

Being aware of that reality and emerging needs, in the University of Coimbra a one-semester CPD course was developed and offered for the first time in academic year $2001 / 2002$. It was conceived as being in itself a product to be designed in order to achieve a number of goals and fulfil a certain number of needs, with a special focus on the adoption of quality principles and quality engineering tools in the product development process. 
The authors' experience in teaching and learning CPD has been very rewarding and it is surprising to realize how much teams of students are able to come up with in the scope of their final CPD projects.

Not simply as a mere coincidence, the simple fact that this article is co-authored by the teacher and a former student of the course who is now doing a $\mathrm{PhD}$ in the field of CPD shows that CPD courses can indeed be really challenging and gratifying experiences, and should become more and more common in Chemical Engineering Departments across the world.

\section{REFERENCES}

Allen, D.T. and Shonnard, D.R., 2002, Green Engineering-Environmental Conscious Design of Chemical Processes (Prentice Hall, Upper Saddle River, NJ, USA)

Altshuller, G., 1996, And Suddenly the Inventor Appeared (Technical Innovation Center, Worcester, USA).

Anderson, N., 2000, Practical Process Research and Development (Academic Press, New York, USA).

Bernardo, F. and Saraiva, P., 2003, Chemical product design under uncertainty: a cosmetic lotion case study, in 4th European Congress of Chemical Engineering, Granada.

Bernardo, F. and Saraiva, P., 2004, Value of information analysis in product/process design, in Proceedings ESCAPE 14, Barbosa-Póvoa, A. and Matos, H. (eds) (Elsevier Science, Amsterdam, The Netherlands), pp 151-156.

Bernardo, F., Pistikopoulos, E. and Saraiva, P., 2001, Quality costs and robustness criteria in chemical design optimisation, Comput Chem Eng, 25: 27-40.

Brennecke, J. and Stadtherr, M., 2002, A course in environmentally conscious chemical process engineering, Comput Chem Eng, 26: 307-218.

Burchill, G. and Brodie C., 1997, Voices into Choices (Joiner, New York, USA).

Charpentier, J.C., 2002, The triplet 'molecular processes-product-process' engineering: the future of chemical engineering?, Chem Eng Sci, 57: 4667-4690.

Constantinou, L., Bagherpour, K., Gani, R., Klein, J.A. and Wu, D.T., 1996, Computer aided product design: problem formulations, methodology and applications, Comput Chem Eng, 20: 685-702.

Cussler, E.L. and Moggridge, G.D., 2001, Chemical Product Design (Cambridge University Press, Cambridge, UK).

Cussler, E.L. and Wei, J., 2003, Chemical product engineering, AIChE J, 49(5): $1072-1075$

Danckwerts, P.V., 1966, Science in chemical engineering, Chem Eng, July/August: CE155-CE159.

Dimancescu, D. and Dwenger, K., 1996, World-Class New Product Development (American Management Association, New York, USA).

Dym, C. and Little, P., 2000, Engineering Design (Wiley, New York, USA).

Favre, E., Marchal-Heusler, L. and Kind, M., 2002, Chemical product engineering: research and educational challenges, Trans IchemE, Pt A, Chem Eng Res Des, 80: 65-74.

Grossmann, I.E., 2003, Challenges in the new millennium: product discovery and design, enterprise and supply chain optimisation, global life cycle assessment, in Proceedings PSE, Chen, B. and Westerberg, A. W. (eds) (Elsevier Sience, Amsterdam, The Netherlands), pp 28-47.

Holliday C.O.Jr, Schmidheiny, S. and Watts, P., 2002, Walking the Talkthe Business Case for Sustainable Development (Berrett-Koehler, San Francisco, USA).
Kind, M. and Schuchmann, H., 2003, KAFEP — a centre for academic research and development in product engineering, in 4th European Congress of Chemical Engineering, Granada.

Kontogeorgis, G.M., Kiil, S., Abildskov, J., Johannessen, T. and DamJohansen, K., 2003, Chemical product design - a new multidisciplinary teaching activity at Institut for Kemiteknik (DTU), in 4th European Congress of Chemical Engineering, Granada.

Lochner, R. and Matar, J., 1990, Designing for Quality (ASQ, Milwaukee, USA).

Moggridge, G.D. and Cussler, E.L., 2000, An introduction to chemical product design, Trans IChemE, Pt A, 78: 5-11.

Moggridge, G.D. and Cussler, E.L., 2003, Teaching chemical product design, in Proceedings PSE, Chen, B. and Westerberg, A. W. (eds) (Elsevier Sience, Amsterdam, The Netherlands), pp 1460-1465.

Phadke, M., 1989, Quality Engineering Using Robust Design (Prentice Hall, Upper Saddle River, USA).

Pires, A., 1999, Inovação e Desenvolvimento de Novos Produtos (Sílabo, Lisboa, Portugal).

Plsek, P., 1997, Creativity, Innovation and Quality (ASQ, Milwaukee, USA).

Rantanen, K. and Domb, E., 2002, Simplified TRIZ-New Problem-Solving Applications for Engineers and Manufacturing Professionals (St Lucie Press, Boca Raton, USA)

Rosenau M.D.Jr, Griffin, A., Castellion, G.A. and Anschuetz, N.F., 1996 The PDMA Handbook of New Product Development (Wiley, New York, USA).

Saraiva, P. and Orey, J., 2000, Inovação e Qualidade (Sociedade Portuguesa de Inovação, Lisboa, Portugal).

Schmidt, S. and Launsby, R., 1992, Understanding Industrial Designed Experiments, 3rd edn (Air Academy Press, London, UK).

Sikdar, S.K. and El-Halwagi, M., 2001, Process Design Tools for the Environment (Taylor \& Francis, New York, USA).

Stamatis, D., 1995, Failure Mode and Effect Analysis (ASQ, Milwaukee, USA).

Stroebe, M., Volker, H.H., Zogg, A., Scheringer, M. and Hungerbuhler, K., 2001, Environmentally oriented design and assessment of chemical products and processes, Chimia, 55: 887-891.

Turton, R., Bailie, R.C., Whiting, W.B. and Shaeiwitz, J.A., 2003, Analysis, Synthesis, and Design of Chemical Processes, 2nd edn (Prentice Hall, Upper Saddle River, USA).

Ulrich, K.T. and Eppinger, S.D., 2003, Product Design and Development, 3rd edn (McGraw-Hill, Boston, USA).

Wesselingh, J.A., 2001, Structuring of products and education of product engineers, Powder Technol, 119: 2-8.

Westerberg A.W. and Subrahmanian, E., 2000, Product design, Comput Chem Eng, 24: 959-966.

Wibowo, C. and Ng, K.M., 2002, Product-centered processing: manufacture of chemical based consumer products, AIChE J, 48(6): 1212-1230.

\section{ACKNOWLEDGEMENTS}

The authors would like to acknowledge all of the chemical engineering students who attended the CPD course in academic years 2001/2002 and $2002 / 2003$, for what they have accomplished, enjoyed and suffered in learning and practicing CPD. Financial support from the Portuguese Foundation for Science and Technology (through POCTI/EQU/32647 research project and $\mathrm{PhD}$ fellowship SFRH/BD/12790/2003) is gratefully acknowledged. The authors also wish to thank referees for their useful and helpful comments.

The manuscript was submitted 1 April 2004, and accepted for publication after revision 19 July 2004. 